\title{
A review of website evaluation using web diagnostic tools and data envelopment analysis
}

\author{
Hassan Najadat, Amer Al-Badarneh, Sawsan Alodibat \\ Department of Computer Information Systems, Jordan University of Science and Technology, Jordan
}

\begin{tabular}{l} 
Article Info \\
\hline Article history: \\
Received Oct 9, 2019 \\
Revised Jan 2, 2020 \\
Accepted Jul 24, 2020 \\
\hline
\end{tabular}

Keywords:

Data envelopment analysis

Data mining

Machine learning

Web evaluation

Web measures

\begin{abstract}
This paper presents a review of the most recently published works of the use of data envelopment analysis (DEA) in the evaluation of websites of different fields such as healthcare, e-business, e-commerce, and e-government. The evaluation of websites is performed using web diagnostic tools (WDTs). Some studies have evaluated e-government websites using WDTs only, while others integrate them with data envelopment analysis. We summarize each study including the country that was conducted in, the size of data set, inputs to DEA, outputs from DEA, the approach used, the tools used, and the results obtained. It also covers whether there is a use of combination between DEA and data mining or machine learning approaches to classify the efficiency of these websites.
\end{abstract}

This is an open access article under the CC BY-SA license.

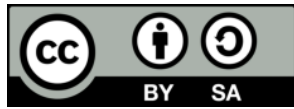

\section{Corresponding Author:}

Hassan Najadat,

Department of Computer Information Systems,

Jordan University of Science and Technology,

Irbid, Jordan.

Email: najadat@just.edu.jo

\section{INTRODUCTION}

Recently, the significance of information technologies has increased as the main component of government reforms. Many governments around the world attempt to gain the benefits of e-government. Government information technology initiatives provide several potential benefits such as productivity, efficiency, effectiveness, transparency and better public participation [1]. The emergence of e-government was initiated in the late of 90s. In that time, e-government referred to the information efficiency in governmental agencies. After 2000, a continuous movement in the world has expanded and affected e-government public services provided to businesses and citizens. Nowadays, e-government has become a response measure of the government towards preparation for fourth industrial revolution [2]. E-government portals include a combination of technological services, information, and applications. In specific, government portals are internet gateways or websites that present online access to government information and services [1]. Further, in many developing countries, e-government projects have been tremendously launched to serve the community through electronic services that improve the quality of public services [3]. On the other hand, few government organizations achieved their goals within time and budget allocation [1]. Many organizations, governments, and developers often neglect the evaluation and test of their websites. However, they only assess them when they get failure or suffer from serious complications [4]. Therefore, governments have to continuously evaluate their performance to make sure that e-government state is consistent with the development.

Indeed, there are diverse models designed to build an application and framework for best results of e-government development [3]. These evaluation models consider outputs that involve information, services 
and other functionalities. Most of them ignore the inputs such as resources and capabilities of governments. Thus, we need more assessment methods that provide better understanding of the efficiency and high quality of government portals. The performance of e-government portals is measured through different levels of functionalities and technical features involved in these portals [1]. In e-government field, there are many approaches from literature have been developed to evaluate websites. However, they differ in information collection methods including heuristics approach, observations, questionnaire, and website evaluation tools. These approaches also differ in their evaluation goals ranging from usability, effectiveness, interface, to quality [5]. The common web metrics of e-government portals, web diagnosis tools, and machine learning concepts are discussed in this section. It draws a general picture of web evaluation measures and the studies that have recommend them. Further, these web measures are calculated using web diagnosis tools that are also summarized below. A brief description of machine learning and data mining is also included. In practices of websites, web performance metric refers to the speed of downloading and displaying webpages on browser. Therefore, higher visitor loyalty, retention, and satisfaction depend on download speeds.

In [6] determined that the good loading time of websites range from 1-5 seconds, while average should be between 5 and 10. Poor loading time websites is more than 10 seconds. When page size is less than or equal to $12 \mathrm{~kb}$ the web page is fast. If the page size is less than or equal to $3 \mathrm{mb}$, the web page is good. Website accessibility means that the users and disabilities can access the whole website. In [7], the common dimensions of criteria used to assess the quality of e-government portals included design quality, content quality, user-friendly quality, and organization quality. Load time and response time are the main parameters used to identify the quality of webpage design including the number and the size of items in a webpage [8]. The paper [9] determined seven predictors of the performance of e-government websites including service, content, usability, functionality, ease of use, accessibility and security/privacy. The usability features were investigated in [10]. The user interface, color combinations, navigations and broken links are major checked measures of usability. The research variables of [11] are represented by characteristics of web services, web metrics and website popularity. The internet-based public services can be measures using sitemap, FAQs, news and events, e-procurement, and promotions. The number of web pages indexed by google, inbound links indexed in yahoo, and the number of files tracked by google are main variables of web metrics. Total HTML finds the number of HTML file, CSS file, CSS images, JavaScript, and multimedia [8]. The following section provides information about the common web diagnostic tools used to evaluate web sites. The study [4] has addressed the use of some web diagnostic tools in evaluation the accessibility of websites.

There are different evaluation tools such as Bobby, Lynx and Cynthis Says that are used as web-based accessibility tools [4]. Website optimization tool [12] was used to evaluate the online performance and speed analysis of websites such as load time and accessibility errors. Whereas check link validator [12], HTML validator, accessibility testing software and link popularity [12] tools were used to measure the broken links, the frequency of update, and the accessibility errors. Other tools are Xenus slw (i.e. for broken links), source code analyzer, link popularity check, chronometer (i.e. access speed), Tawdis tester, google analytics, Alexa, Page Rank, web traffic, and web ranking [4]. A complete reference of accessibility evaluation tools is found in $\mathrm{W} 3 \mathrm{C}$ including Infocus, ramp and a-prompt are examples of accessibility tools. Some tools are freely or commercially available. A complete analysis of website accessibility is performed through eXaminator, Total validator, TAW, MAGENTA, HERA, and Amp [13]. For accessibility measure, 508 checker, WAVE webaim [6], and A-tester (evaluera) are used. The use of HTML5 can be assessed using webaim tool. HTML check and repair is an automatic usability evaluation tool that extracts the number of HTML errors per website. It can check the markup validity in different formats like SMIL, XHTML, MathML, and HTML [8]. Fast link checker is used by [14] to evaluate the navigation usability like site broken links. SortSite [15] was used to calculate the number of compatibility problems and the privacy policy issues and warnings. Websitepulse is a tool used to find response time, while pingdom tool [6, 16] calculates the time required to load page and its graphics. W3C validator include W3C markup validator, W3C HTML validator, W3C CSS validator, W3C link checker, and W3C checklink [4]. CSS validator is a free service provided by $\mathrm{W} 3 \mathrm{C}$ used to evaluate the stylesheets of webpages in terms of their conformance with CSS specifications and standards of W3C. it finds the CSS errors, risks of usability, typos and incorrect uses [12]. Site $24 \times 7$ tool monitors the performance, response time, and availability of website [17].

WebtoolHub is an evaluation tool of load time, average speed and page size. Site speed checker also evaluates speed, load time, response time and page size. Google page speed assesses the overall performance according to HTML5. Webpage speed analyzer was also used to evaluate the response time, download time, number and size of items. Page scoring defines different factors for performance including page size, average size, and load time. WebWait is a tool that presents accurate load speed considering image loading and ajax processing. GTmetrix is also used to measure page size, number of requests, and load time. Yslow tool developed by yahoo is used to analyze web page performance according to the rules of high-performance 
basis of yahoo [16]. WAI list includes 3.08 a standalone version of TAW and a software accessibility testing tool called tawdis. It is a free java tool [18]. Maximine tool finds the number of visitors, number of page hits, and response time of site. It assesses the interaction and behavior in downloading files, streaming media like lash, HTML. For security test, [8] used Acunetix Web Vulnerability Scanner 10.5 and NetSparker Community Edition Web Vulnerability Scanner as performing well in scanning and finding XSS and SQLI vulnerabilities without authentication. WebCPO is a security evaluation tool. Other tools like WebTango that is used for classifying website tools [4]. Web page size lookup tool presents useful information about website size. GSiteCrawler Tool is used to evaluate the website in terms of the updates happened on the site and the latest amendments to help search engine in making more accurate searches and rankings [17].

Machine learning (ML) or data mining, terms are used alternatively, can be defined as the process of enhancing the measure of performance to resolve any problem using computerized and automated methods. The advent of ML and DM have dramatically advanced the practice of computer vision, natural language processing, speech recognition, etc. Moreover, it showed its wide range of impact in many domains such as biology, social science, computer science, and many others. The main goal of deployment of ML and DM is to develop new methods for high throughout experimental analysis [19]. Due to its applicability to incorporate prior knowledge, the learning process of ML contributes to success many learning algorithms. It composes the development of various tools to be implemented in expressing the learning bias and domain expertise that much depends on the theory of ML [20]. Data mining techniques involves clustering, classification, prediction, association, etc.

\section{LITERATURE REVIEW}

In this section, we provide a review of the related works that have used data envelopment analysis (DEA) in evaluating the quality and efficiency of websites in different fields. These studies used different groups of inputs, outputs, model, and application domain. The number of these studies is relatively small and there is a variance between studies in terms of application field, dataset size, inputs and outputs. In [2], Seo et al., 2018 examined Gov. 3.0 (e-government) efficiency of 42 central administrative agencies in Republic of Korea. Three factors: citizen-centric service integration, IT investment for system construction, and separate IT integration centre were the most important factors affecting Gov. 3.0 efficiency. There were 2 inputs and 3 outputs to DEA. Inputs included IT budget and No. of employees, while outputs were No. of policies for the adoption of Government 3.0, No. of open public data (API), and No. of public services that can be applied for online. They implemented output-oriented focus but implemented BCC and CCR. Lo Storto, 2009 measured the quality and usability of 40 websites in terms of relative efficiency. The data source was obtained through questionnaire data collection. 6 inputs included ambiguity, uncertainty, time (structure), ambiguity, uncertainty, and time (navigability). 3 outputs included usefulness, satisfaction and attractiveness. CCR model was applied. The results showed that 5 out of 40 websites were efficient [5].

Jin, 2011 in [21] evaluated nine e-business targets to increase the e-business performance. 30 variables were considered such as download time, help features, dynamic content, sending in time, and online FAQ. All the data were collected using efficiency measurement system (EMS) software that includes system quality, information quality and the service quality. El-Aleem et al., 2005 [22] measured the efficiency of nine real-world e-commerce websites. Siz inputs were considered to DEA including home page response time, average page size $(\mathrm{KB})$, total number of pages, distinct number of foreign sites referenced, percent of pages requiring two or more links to reach, and percent of pages greater than $60 \mathrm{~KB}$. The outputs included average daily hits and average daily unique visitors. The results showed that 4 out of 9 websites are efficient. They used MaxamineTM web analyst tool. In [23], Alzua-Sorzabal et al., 2015 evaluated the tourist websites of three cities in Basque country. The inputs involved number of supported languages, GlobalSeoRank, SpainSeoRank, MaintenanceCost, MaintainersNumber, structure depth, and web content update. The outputs were visits number and average time on site. They used Destination Web Monitor (DWM) to collect variables from websites. R language was used for DEA.

Kao et al., 2013 in [24] evaluated web security efficiency of 91 hospitals in Taiwan. They considered 10 inputs classified into three categories: clarity of purpose, communication, and security framework. They include security information, security measures, security policy, News or events, fault detection, updated content, transmission platform, help desk services, security protocols, and security risks. The outputs were user satisfaction and progress of ISO 27001 accreditation. Data collected by reviewers from the websites of hospitals. Support vector machine analysis was applied for data analysis. The outcomes showed that 29 out of 91 hospitals websites were efficient. In [2], Jadi \& Jie, 2017 evaluated the e-government performance in 8 countries. 3 inputs included online service index, human capital index, and telecommunication index, while 1 output was e-participation index. Data collection was done by expert 
assessment surveys based on the indicators of online service, telecommunication infrastructure, human capacity, and e-government development.

Luna et al., [1] have evaluated electronic government portals in Mexico of 32 e-government websites. Six inputs were carried out including number of internet users, number of computers users, number of mobile phones users, global competitiveness index, government efficiency index, and infrastructure index. The outputs included information, interaction, transaction, integration, and participation. The results showed that 8 of 32 e-government websites were efficient [1, 25]. Hahn [26] has used the theoretical perspective of production economics to evaluate the performance of internet based selling websites using CCR DEA. The inputs to the model included customer consume inputs and various functionalities of the website such as number of product page views, number of product lists views, number of personal list views, number of orders history page views, number of research conducted, number of promotional page views, number of recipe page views, number of checkout pages, and number of help page views. The outputs included basket full of items at checkout or number of items at checkout. WebTrends data mining and website analysis tool was employed to report who visit the website, number of hits for a given data range, HTML errors, and website usage statistics.

The paper of Najadat et al., [17] has proposed a new approach proposed to evaluate the 23 Jordanian universities websites using DEA. The websites were evaluated in three viewpoints: design, performance, and usability. The inputs selected included response time, page size, number of pages, number of sites refer to the website, and the percentage of pages that require little links to reach site. The outputs included average time of daily visitors and average page view. They used Maximine tool to find the number of visitors, the number of page hits, and the number of external links refer to the website. GSiteCrawler was also used to find the number of pages in the website. Site $24 \times 7$ tool was used to measure the response time, web page size, and the website size. They used DEAP tool for DEA and they applied CCR. In terms of usability, 18 websites were usable while 5 not. Only 7 websites have good design. 4 websites were efficient and 19 were inefficient.

Lyócsaa [27] proposed an application of imprecise DEA model to set and measure web search engines by measuring searching task efficiency. The approach has been applied on 337 students during two years in web searching experiment such as domain specific and domain neutral search tasks. The data collection was done by e-learning web browser-based module. Input variables included the number of correct answers and time spent to complete each task. Outputs included information to measure of success in getting the information searched such as the validity of the answer for domain specific one answer and rank among test group for domain neutral more correct answers. Deng [28] provided a website evaluation as indicator of efficiency for agricultural websites. Seventeen municipal websites in Shandong province were analyzed using CCR model of DEA. The inputs included total number of web pages, average page size, total foreign sites that link to the site, update rating, number of broken links, foreign pages references, non-returning percentage, and connected percentage. The output involved number of visitors. Maximine tool was used for analysis of the websites. Alexa tool was also used to consult verified test result of output. The findings showed that 3 of websites were efficient but 14 were not forming $84 \%$.

\section{RESEARCH METHOD}

The contributions of this study are exposed as follows. This study tries to close the gap in the state of the art, which is the lack of evidence about the web evaluation tools, metrics, and standards for e-government portals. This survey outperforms other studies in terms of the novelty of studies reviewed in this research and the inclusion of the most recent researches in this field. Moreover, it presents a comprehensive overview of the application of DEA in multiple fields specialized in web evaluation. Hence, we provide a comprehensive insight of the different dimensions of e-government websites evaluation. This survey shows the most common web metrics regarding design, speed, size, etc., web diagnosis tools of web evaluation, and the studies that have integrated other methods in their evaluation of e-government websites. In this section, we provide some web metrics of e-government portals for better provision of services.

The work of [11] has divided the e-government evaluation measures into two main groups. The first group includes input, output and impact of e-government, while the second group encompasses measure of efficiency, service quality and e-government activities. Similarly, in [29], seven categories were defined including navigation, accessibility, information content, visual design, ownership, interactivity, and usability. Reference [30] aimed to evaluate the credibility and usability of the government websites by finding the corresponding problems through examining the easy forward and backward, A-Z quick service, images with context, personal service protection, and key information location. In Turkey, 51 government websites were evaluated based on usability metrics to evaluate the websites internal attributes. The measures included loading time, HTML errors, and browser compatibility [14]. In [13], 25 official websites were analyzed in Turkey in terms of web accessibility. The accessibility and usability of 79 Tanzania e-government websites 
in terms of web security vulnerabilities were measured. The main error evaluated was 404-error page that indicates of the responding web server but not found page because of inexistence of the website link [6]. An evaluation of 21 e-government websites in Dubai was achieved in [18] in terms of web accessibility. Moreover, a set of 30 web-based services of e-government websites were evaluated in terms of usability, accessibility, responsiveness, and transparency [15].

DEA is a very useful non-parametric, linear programming and optimization tool used to analyze, measure, and estimate the performance and productivity of decision-making units (DMU) that yield to improve their efficiencies [17, 31]. DEA is an extensively used technique that can identify the efficiency considering inputs and outputs in any unit intended to be studied. It aims to improve the productivity of these units by providing a comprehensive way that uses built measures of evaluation models and help organizations to attain their desired outcomes using their existing resources [1]. DEA can be applied successfully on many application domains. The efficiency can be defined as the ratio of weighted sum of outputs over the weighted sum of inputs. DEA was developed by Charnes, Cooper and Rhodes (CCR) [17]. Efficiency is the unit cost ratio that measures the relation between the amount of output and the amount of input of services [32]. Thus, efficiency measure also considers a cost per transaction and data errors tracked from electronic services delivery compared to the traditional ones [33]. The relative efficiency is between 0 and 1 [33]. As shown in (1), the efficiency can be measures through dividing the summation of weighted outputs on the summation of the weighted inputs.

$$
\text { Efficiency }=\frac{\text { Nweighted outputs }}{\sum \text { weighted inputs }}
$$

In (2), as well as (3), the max function is used to maximize the outputs using the inputs.

$$
\max =\frac{\sum_{k=1}^{S} v_{k} y_{k i}}{\sum_{j=1}^{m} u_{j} x_{j i}}
$$

Such that

$$
\max =\frac{\sum_{k=1}^{S} v_{k} y_{k i}}{\sum_{j=1}^{m} u_{j} x_{j i}} \leq 1, \forall i \quad v_{k}, u_{j} \geq 0 \forall k, j
$$

where $k=1$ to $s$ outputs, $j=1$ to $m$ inputs, $i=1$ to $n$ DMUs, $y_{k i}$ is the amount of output $k$ produced by DMU $i, x_{j i}$ is the amount of input $j$ utilized by DMU $i, v_{k}$ is the weight of output $k, u_{j}$ is the weight of input $j$.

DEA models are divided into input oriented and output oriented. If we consider input oriented, we would be concerned in reducing inputs and minimizing inputs costs but keeping output at present level (or maximized) at the same time. Conversely, output oriented model is concerned with increasing outputs but to keep input at the present level and amount. The main similarity between input oriented and output oriented is the identification of the same efficient frontier [34]. Two basic models of DEA are BCC and CCR, where (Banker-Charnes-Cooper) BCC (also called variable returns to scale VRS) considers that, the efficiency of production is not dependent to the proportionality relationship between inputs and outputs. Thus, BCC model assumes that the efficiency of DMU depends on the good use of inputs regardless higher scales that can operate. On the other hand, (Charnes-Cooper-Rhodes) CCR (also called constant returns to scale CRS) assumes the use of constant returns to scale by maximizing the ration between the outputs and inputs but not exceeding one. When the DMU presents the best ratio of outputs in relation to inputs, the efficiency will be guaranteed in CCR model. Both BCC and CCR are considered input oriented or output oriented. The choice of orientation should be taken considering the conditions and the goals of the system [35-36].

\section{RESULTS AND DISCUSSION}

As shown from reviewed literature about the use of DEA in evaluating websites, we can draw the potential works for future studies to guide the researchers of the important domains that need to apply DEA efficiency tool of evaluation. Different studies have applied the use of DEA in evaluating various websites in different domains like e-commerce, e-government, universities, agriculture websites, search engines, tourist, hospitals, and so on. However, these studies are not sufficient, and we need to put more focus and effort on evaluating websites in different domains. We divide the studies that have applied DEA with web evaluation tools to assess web portals into different categories based on the domain they applied.

More specifically, we classified them into e-government, e-commerce, and other domains. This study provides a comprehensive overview of the e-government development and how they are evaluated based on web metrics and using web evaluation tools. Table 1 shows a summary of the reviewed work showing the domain of e-government, including the inputs of DEA, outputs of DEA, the model applied, and the size of the dataset. 
Table 1. Studies of e-government DEA evaluation

\begin{tabular}{|c|c|c|c|c|}
\hline Ref. & Inputs & Outputs & Model & Size \\
\hline$[2]$ & IT budget and no. of employees & $\begin{array}{l}\text { No. of policies, open public data, and } \\
\text { public services }\end{array}$ & $\begin{array}{l}\mathrm{BCC} \\
\mathrm{CCR}\end{array}$ & 42 \\
\hline [3] & Index of online service, human capital, and telecommunication & E-participation index & & 8 \\
\hline$[1,25]$ & $\begin{array}{l}\text { Number of internet users, computers users, mobile users, index of } \\
\text { global competitiveness, government efficiency, and infrastructure }\end{array}$ & $\begin{array}{l}\text { Information, interaction, transaction, } \\
\text { integration, and participation }\end{array}$ & VRS & 32 \\
\hline$[2]$ & IT budget and no. of employees & $\begin{array}{l}\text { No. of policies, open public data, and } \\
\text { public services }\end{array}$ & $\begin{array}{l}\mathrm{BCC} \\
\mathrm{CCR}\end{array}$ & 42 \\
\hline
\end{tabular}

Table 2 also shows a summary of the reviewed work showing the domain of e-commerce. Moreover, there should be a focus on evaluating e-government websites considering the appropriate inputs and outputs corresponding to their websites. Furthermore, CCR model is the mostly used model of DEA. Thus, there is a need to apply BCC model in different studies or both of them and make a comparison between their results.

Table 2. Studies of e-commerce DEA evaluation

\begin{tabular}{|c|c|c|c|c|}
\hline Ref. & Inputs & Outputs & Model & Size \\
\hline [29] & $\begin{array}{l}\text { Number of products, product lists, personal lists, orders } \\
\text { history, researches conducted, promotional views, } \\
\text { recipe page views, checkout pages, and help page views }\end{array}$ & Number of items in basket at checkout & CCR & - \\
\hline
\end{tabular}

Moreover, Table 3 also shows a summary of the reviewed work showing the domain of other domains like tourists, universities, hospitals and agricultures. There was a focus on some web metrics such as number of visitors, average time on website, size of website, and speed. Indeed, we need to use other web metrics to be considered in the evaluation.

Theoretically, it highlighted the main concepts, measures, techniques, tools, and approaches used to evaluate e-government portals. It also set the basics for web evaluation tools used indifferent fields. In practice, this study shows the practical implementation of using DEA and data mining to evaluate websites. Moreover, it put emphasize on the setting of inputs, outputs, type of DEA model, and the fields that have been investigated.

Table 3. Studies of DEA evaluation in other domains

\begin{tabular}{|c|c|c|c|c|}
\hline Ref. & Inputs & Outputs & Model & Size \\
\hline [23] & $\begin{array}{l}\text { Number of supported languages, global SEO rank, Spain SEO rank, } \\
\text { maintenance cost, maintainers number, structure depth, and web } \\
\text { content update }\end{array}$ & Visits number and average time & $\begin{array}{l}\text { CRS } \\
\text { VRS }\end{array}$ & 3 \\
\hline [17] & $\begin{array}{l}\text { Response time, page size, number of pages, number of sites refer to the } \\
\text { website, and the percentage of pages require little links to reach site }\end{array}$ & $\begin{array}{l}\text { Average time of daily visitors } \\
\text { and average page views }\end{array}$ & CCR & 23 \\
\hline
\end{tabular}

After investigating the related work, we can provide a set of recommended web evaluation tools and significant web evaluation criteria to be focused in the research. One of the possible concerning questions for more investigation in this field is how to integrate data mining algorithms and DEA analysis to evaluate the efficiency of the algorithms. A different side of deserving research is to conduct the aspects of how to deeply examine the web diagnosis tools in terms of their work and internal structure. For future studies, there are many opportunities could be exploited to apply DEA models combined with the use of web diagnostic tools to evaluate websites based on specific metrics. Finally, the size of the datasets used in different studies is quite small and not adequate. Hence, larger datasets should be collected or used in evaluating websites. 


\section{CONCLUSION}

From this survey, there are many investigating studies on the use of web diagnostic tools in evaluating websites. However, there are a few studies investigated on the use of DEA combined with web diagnostic tools to evaluate websites. We review the literature about the most common web metrics used to evaluate e-government websites. Further, we compare between the studies that have used DEA combined with web metrics for the evaluation of websites of different fields such as healthcare, education, e-commerce, and e-government. These studies have evaluated the studied websites performed using web diagnostic tools (WDTs). Some studies have evaluated e-government websites using WDTs only, while others integrate them with DEA. We summarize each study including the country that was conducted in, the size of data set, inputs to DEA, output of DEA, the algorithm applied, the approach used, the tools used, and the results obtained. It also showed if there is an inclusion of data mining or machine learning approaches with DEA to analyze, classify, and predict the efficiency of these websites. Finally, we provide a set of directions for future investigation in this area of research.

\section{REFERENCES}

[1] D. Luna, J. Gil-Garcia, L. Luna-Reyes, R. Sandoval-Almazan \& A. Duarte-Valle, "Improving the performance assessment of government web portals: A proposal using data envelopment analysis (DEA)," Information Polity, vol. 18, no. 2, pp. 169-187, 2013.

[2] I. Seo, Y. Kim \& J. Choi, "Assessment of efficiency in public service-focused on Government 3.0 case in Korea," Total Quality Management \& Business Excellence, vol. 29, no. 9-10, pp. 1161-1184, 2018.

[3] Y. Jadi \& L. Jie, "An Efficiency Measurement of E-Government Performance for United Nation Ranking Index," International Journal of Social, Behavioral, Educational, Economic, Business and Industrial Engineering, vol. 11, no. 1, pp. 279-282, 2017.

[4] D. Zahran, H. Al-Nuaim, M. Rutter \& D. Benyon, "A comparative approach to web evaluation and website evaluation methods," International Journal of Public Information Systems, vol. 10, no. 1, pp. 21-39, 2014.

[5] C. Lo Storto, "A distributed cognition framework to compare e-commerce websites using data envelopment analysis," International Journal of Computer, Electrical, Automation, Control and Information Engineering, vol. 3, no. 4, pp. 863-871, 2009.

[6] N. Elisa, "Usability, accessibility and web security assessment of e-government websites in Tanzania," International Journal of Computer Applications, vol. 164, pp. 42-48, 2017.

[7] L. Hasan \& E. Abuelrub, "Assessing the quality of web sites," Applied Computing and Informatics, vol. 9, no. 1, pp. 11-29, 2011.

[8] Y. Akgul, "Web Site Accessibility, Quality and Vulnerability Assessment: A Survey of Government Web Sites in the Turkish Republic," Journal of Information Systems Engineering \& Management, vol. 1, no. 4, pp. 1-13, 2016.

[9] E. Abu-Shanab \& A. Baker, "Evaluating Jordan's e-government website: a case study," Electronic Government, an International Journal, vol. 8, no. 4, pp. 271-289, 2011.

[10] M. IFawwaz, "Evaluation of eGovernment Websites usability in Jordan," Ph.D. dissertation, Brunel University, 2012.

[11] B. Hermana \& W. Silfianti, "Evaluating e government implementation by local government: digital divide in internet based public services in Indonesia," International Journal of Business and Social Science, vol. 2, no. 3, 2011.

[12] H. Jati, "Performance Evaluation on Quality of Asian Airlines Websites-AN AHP Approach," In Proceedings of the $4^{\text {th }}$ International Conference on E-Commerce with Focus on Developing Countries, pp. 3-4, 2009.

[13] Y. Akgul \& K. Vatansever, "Web accessibility evaluation of government websites for people with disabilities in Turkey," Journal of Advanced Management Science, vol. 4, no. 3, 2016.

[14] Y. Akgül, "Quality evaluation of E-government websites of Turkey," In Proceedings of the $11^{\text {th }}$ Iberian Conference on Information Systems and Technologies, pp. 1-7, 2016.

[15] A. R. Al-Soud and K. Nakata, "Evaluating e-government websites in Jordan: Accessibility, usability, transparency and responsiveness," In Proceedings of the International Conference on Progress in Informatics and Computing, pp. 761-765, 2010.

[16] T. Al Balushi, S. Ali, R. Ashrafi \& S. AlBalushi, "Accessibility and Performance Evaluation of E-Services in Oman Using Web Diagnostic Tools," International Journal of u-and e-Service, Science and Technology, vol. 9, no. 7, pp. 9-24, 2016.

[17] H. Najadat, A. Al-Badarneh, R. Al-Huthaifi, A. Abo-Zaitoon and Y. Al-Omary, "Evaluating Jordanian universities' websites based on data envelopment analysis," In Proceedings of the $8^{\text {th }}$ International Conference on Information and Communication Systems, pp. 159-164, 2017.

[18] B. Al Mourad \& F. Kamoun, "Accessibility evaluation of Dubai e-government websites: Findings and implications," Journal of E-Government Studies and Best Practices, vol. 2013, Article ID 978647, 2013.

[19] M. Jordan \& T. Mitchell, "Machine learning: Trends, perspectives, and prospects," Science. vol. 349, no. 6245, pp. $255-260,2015$.

[20] S. Shalev-Shwartz \& S. Ben-David, "Understanding machine learning: From theory to algorithms," Cambridge University Press, 2014.

[21] Ying Jin, "On the performance evaluation model based on data envelopment analysis," In Proceedings of the International Conference on Computer Science and Network Technology, pp. 250-253, 2011. 
[22] A. El-Aleem, W. El-Wahed, N. Ismail \& F. Torkey, "Efficiency Evaluation of E-Commerce Websites," Journal of World Academy of Science, vol. 2, pp. 20-23, 2005.

[23] A. Alzua-Sorzabal, M. Zurutuza, F. Rebón \& J. Gerrikagoitia, "Obtaining the efficiency of Tourism Destination website based on Data Envelopment Analysis," Procedia-Social and Behavioral Sciences, vol. 175, pp. 58-65, 2015.

[24] H. Kao, T. Chang \& Y. Chang, "Classification of hospital web security efficiency using data envelopment analysis and support vector machine," Mathematical Problems in Engineering, vol. 2013, Article ID 542314, 2013.

[25] D. Luna, J. Gil-Garcia, L. Luna-Reyes, R. Sandoval-Almazán \& A. Duarte-Valle, "Using data envelopment analysis (DEA) to assess government web portals performance," In Proceedings of the $13^{\text {th }}$ Annual International Conference on Digital Government Research, pp.107-115, 2012.

[26] S. Lyocsa, Z. Cyril, V. Tomas \& B. Eduard, "Measuring Web Searching Task Efficiency: An Imprecise Data Envelopment Analysis Approach," SSRN, 2 April 2012.

[27] S. Deng \& M. Weili, "Evaluation on the Agricultural Website's Efficiency Based on DEA Method," In Proceedings of the International Conference on Computer and Computing Technologies in Agriculture, pp. 674-680, 2010.

[28] D. Katre \& M. Gupta, "Expert usability evaluation of 28 state government web portals of India," International Journal of Public Information Systems, vol. 7, no. 3, 2011.

[29] J. Hahn, "Measuring the effectiveness of e-commerce website design and its impact on business value," Ph.D. dissertation, University of Minnesota, Minnesota, United States, 2003.

[30] Z. Huang, "Usability and credibility evaluation of electronic governments: users' perspective," M.S. Thesis, School of Information Systems, Computing and Mathematics, Brunel University, 2010.

[31] A. Gupta, M. Kohli and N. Malhotra, "Classification based on Data Envelopment Analysis and supervised learning: A case study on energy performance of residential buildings," In Proceedings of the $1^{\text {st }}$ International Conference on Power Electronics, Intelligent Control and Energy Systems, pp. 1-5, 2016.

[32] Abdullahi Iliyasu, Zainal Abidin Mohamed, Rika Terano, "Data envelopment analysis models and software packages for academic purposes," Pertanika Journal of Scholarly Research Reviews, vol. 1, no. 1, pp. 27-32, 2015.

[33] A. Charnes, W. Cooper, E. Rhodes, "Measuring the efficiency of decisionmaking units," European Journal of Operational Research, vol. 2, no. 6, pp. 429-444, 1978.

[34] D. Luna, J. Gil-Garcia, L. Luna-Reyes, R. Sandoval-Almazán \& A. Duarte-Valle, "Using data envelopment analysis (DEA) to assess government web portals performance," In Proceedings of the $13^{\text {th }}$ Annual International Conference on Digital Government Research, pp. 107-115, 2012.

[35] J. Grilo, "Performance evaluation using data envelopment analysis: the case of general cargo terminals," M.S. Thesis, Autonomous Section of Naval Engineering, Instituto Superior Técnico, Universidade de Lisboa, 2013.

[36] K. AlKhathlan \& S. Malik, "Are Saudi banks efficient? Evidence using data envelopment analysis (DEA)," International Journal of Economics and Finance, vol. 2, no. 2, pp. 53-58, 2010.

\section{BIOGRAPHIES OF AUTHORS}

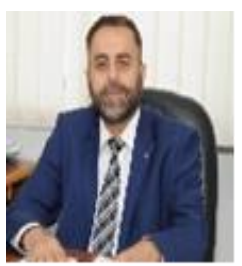

Hassan Najadat is an Associate Professor of Computer Science at Jordan University of Science and Technology. He earned his Ph.D. in Computer Science from North Dakota State University, $\mathrm{ND}$, USA in 2005. His research interests include analyzing datasets using data mining techniques to develop intelligence applications in data envelopment analysis, text mining, sentiment analysis, health information, educational data mining, security, and data envelopment analysis. He has published more than 50 papers on data mining.

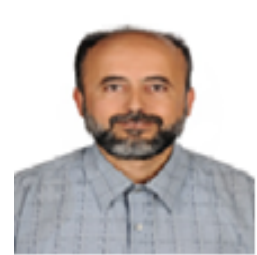

Amer Al-Badarneh is a Data Science Professor. He received the B.Sc. degree (with honors) in Computer Science from Yarmouk University, Jordan, in 1987 and a PhD degree in Computer Science from Wayne State University, Michigan, USA, in 2000. He joined the Department of Computer Science, Jordan University of Science and Technology (JUST), Jordan. His research interests are in the areas of big data management and analytics, data mining, information retrieval, natural language processing, spatial data indexing, and evolutionary computation.

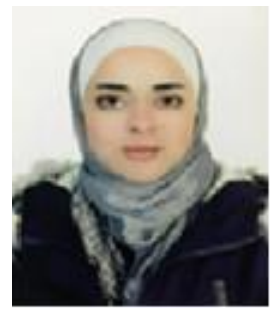

Sawsan Alodibat born received her master's degree in computer science from Jordan University of Science and Technology (JUST), Jordan, in 2019. She is currently working at Department of Civil Status and Passport, Jordan. Sawsan worked as a teacher assistant at Jordan University of Science and Technology (JUST) between 2015 and 2018. She also served as a researcher at Passion Company for Research and Development. Her research interests including Machine Learning and Data Envelopment Analysis. Alodibat has published many articles in networks and machine learning. 